\title{
Cibercultura: adaptación y psicopatología
}

RESUMEN: El marco histórico actual lleva a la reflexión sobre el papel que «la interacción entre el hombre y la máquina» está jugando en la salud mental. Arbitrar mecanismos para que tal relación no genere patología es una propuesta de futuro.

PALABRAS CLAVES: Nuevas tecnologías, Internet, psicopatología, adaptación.
SUMMARY: Present historic setting takes us to the clear reflection that «interaction between man and machine» is playing a role in the state of mental health. The findings of mechanisms, so that said relation does not generate pathologies, is a proposal for the future.

KEY WORDS: New technologies, Internet, psychopathology, adaptation.

\section{Introducción}

Entendemos por cultura «aquella que recoge la suma de conceptos, modos de pensar, actitudes y patrones de comportamiento de los individuos en su entorno social». Está presente en todas las características y actividades del ser humano. La impulsa la capacidad de crear imágenes, símbolos y estructurarlos de forma compleja que pueden ser codificados por el lenguaje. Afecta a las emociones y a las conductas, definiéndolas y regulando los impulsos instintivos (1).

Todas las culturas desarrollan procesos que facilitan la adaptación y presiones que favorecen el conflicto, la desviación y la inadaptación. En la era moderna las culturas cambian a velocidad creciente generando sus propios factores de estrés.

Con la aparición de las nuevas tecnologías de la información se han acuñado nuevos conceptos: la cibercultura, la cultura audiovisual, el ciberespacio. En ella se incorporan nuevas prácticas sociales en las que la frontera espacio/tiempo se vuelve borrosa y la interactividad se impone en el proceso de comunicación. Su inclusión en la vida diaria hace imprescindible conocer de qué manera su utilización va transformando la realidad y cómo esta nueva realidad afecta nuestra manera de ser en el mundo.

Internet, que comenzó siendo una tecnología de la información, pasa a ser concebida hoy como tecnología social donde los individuos satisfacen sus necesidades individuales y sociales. La gran cantidad de información a la que se puede acceder contiene casi todos los conocimientos y pasatiempos del quehacer humano: la gran biblioteca de la información.

El abaratamiento de los costes de conexión, las mejoras tecnológicas, la llegada masiva de los ordenadores a los hogares lo convierten en una herramienta para la investigación, ocio y negocio. Permite crear grupos, asociaciones, comunidades virtuales, eliminando las barreras geográficas. Se trata de un instrumento globalizador que pone en manos del usuario un medio hasta ahora desconocido, 
de proporciones inimaginables en el futuro. Con el desarrollo y el crecimiento exponencial de usuarios han aparecido los primeros casos de psicopatología asociada al concepto de adicción a la red comprobándose empíricamente la capacidad reforzante de su uso y los condicionamientos asociados.

\section{El lenguaje: comunicación verbal y no verbal}

El lenguaje desde los comienzos de la especie humana basado en la comunicación no verbal, pasando por su racionalización en forma de un lenguaje hablado, ha sufrido una profunda transformación con la llegada de las nuevas tecnologías y la comunicación interactiva. Paul Watzlawick en su Teoría de la comunicación la describe como condición sine qua non de la vida humana y el orden social: «Desde el comienzo de su existencia, un ser humano participa en el complejo proceso de adquirir las reglas de la comunicación, ignorando casi por completo en qué consisten» (2).

Esas reglas se basan en que no es posible no comunicar, que lo importante no es lo que se dice, sino lo que se entiende; que si el que escucha entiende mal, es responsabilidad del emisor el aclararlo; que en toda comunicación decimos cosas (lenguaje digital: lo relativo al contenido) y expresamos emociones (lenguaje analógico: despierta significados a nivel relacional, que pueden ser diferentes para el que los emite y para el que los recibe atribuyendo valores positivos o negativos siendo origen de conflictos) y que en toda comunicación existe un intercambio (3).

En función del contenido del mensaje se establecen distintos canales: el verbal (30-35\%), el no verbal (65-70\%) y el paraverbal (se refiere a aspectos de la palabra hablada capaces de variar su sentido pero no su contenido como la elevación y el descenso en el tono de la voz, el énfasis o la entonación, cómo acentuamos las palabras, el ritmo o la velocidad de la conversación).

En toda comunicación, sin que se den circunstancias adversas para el emisor ni el receptor, las pérdidas del mensaje se cifran en torno a un $80 \%$ en función de los múltiples elementos que la conforman. El peso de cada canal de comunicación en el impacto de los mensajes son: en el lenguaje verbal de un 10-20\%, en el no verbal de un $40-50 \%$, en el paraverbal de un $40 \%$.

Los niveles en que se sucede la comunicación son de una gran complejidad $\mathrm{y}$ van desde lo que el emisor quiere expresar, el pensamiento que construye, lo que se dice, lo que oye el receptor, lo que entiende, lo que entiende del mensaje, lo que asimila o razona del contenido y si actúa o responde adecuadamente.

Independientemente de las culturas, de los grupos humanos se dan aspectos comunes en la interpretación de las señales no verbales; estamos tan acostumbra- 
ORIGINALES Y REVISIONES

dos a observar las expresiones faciales y las posturas que encontramos difícil comunicarnos sin ver a la otra persona cara a cara; las expresiones faciales de alegría, tristeza, miedo, ira, desprecio.

Los elementos de la comunicación no verbal más importantes son: la mirada (tanto para escuchar como para expresar); los gestos (algunos aceptados por todos socio-culturalmente, otros que sirven para apoyar el contenido: los ilustradores, los reguladores, los adaptadores que buscan el acomodo ante una sensación interna de incomodidad); las posturas; una sonrisa; la apariencia personal; el contacto físico que puede ser parte importante en la comunicación y relación humana cuando faltan las palabras (un abrazo, un beso); la proxémica (aquellos aspectos que se refieren a la distancia o proximidad física). A $15-45 \mathrm{~cm}$, sólo se permite la entrada a personas a las que nos sentimos emocionalmente ligados (zona íntima). A $46 \mathrm{~cm}-1.22 \mathrm{~m}$, en una reunión social en el trabajo (zona personal). A $1.23 \mathrm{~m}$ $3.6 \mathrm{~m}$, la que nos separa de los extraños (zona social). A más de $3.6 \mathrm{~m}$, la distancia cómoda para dirigirnos a un grupo de extraños (zona pública) (3).

Otro factor fundamental en la comunicación es la percepción: proceso por el cual la información que se recibe a través de los sentidos se procesa en el cerebro y se almacena en la memoria, produciendo alguna respuesta física o mental; obtenemos la información del entorno a través de los sentidos desarrollando la capacidad de distinguir, etiquetar, categorizar, comparar, etc., y, a su vez, formar juicios (3).

Los factores que influyen sobre las percepciones son psicológicos (aprendizaje, personalidad, creencias y opiniones, autoimagen) y sociológicos (cultura, clase social, grupos de convivencia y la familia). Pero la percepción puede jugarnos una mala pasada cuando se convierte en un obstáculo para relacionarnos y comunicarnos. Generalmente percibimos la información de forma diferente según sea favorable o desfavorable. Sabemos además que es selectiva; de todos los estímulos que reciben nuestros sentidos, unos son captados con más facilidad que otros, y nuestros recuerdos son siempre más fieles a aquello que hemos prestado atención a un nivel consciente.

Existen dos cuestiones decisivas que explicarían esta selección: la intensidad de los estímulos (influye la contundencia, la reiteración, la variación con la que se produce) y la actitud personal (estado mental influido por sentimientos y tendencias de pensamiento y de acción).

\section{La comunicación interactiva}

En la era de la digitalización, las nuevas tecnologías han reestructurado las formas de interaccionar de los individuos modificando sus percepciones a través 
de medios de comunicación virtual en tiempo real (chat, webtelefonía, videoconferencias) y diferido (correo electrónico). Lo virtual sería la cualidad de este tipo de comunicación que alude a la ausencia de una proximidad física. La interacción que se establece a través de Internet tiene características particulares: en el ciberespacio el usuario no necesita «ver» al otro para comunicarse, no existe la apariencia física, el tono e inflexiones de la voz, los gestos, etc. El internauta puede desconocer el país y la ciudad de donde proviene su interlocutor: es lo que decide ser en cada momento.

Lameiro (4) señala que la Red posibilita el encuentro y la comunicación entre personas de latitudes muy diversas. La ausencia de la percepción directa del cuerpo y su inaccesibilidad en el ciberespacio constituyen un límite cuyos efectos intersubjetivos son paradójicos, pues es vivido a la vez como defecto y como posibilidad. La ausencia de una presencia física entre usuarios interconectados demanda la puesta en práctica de nuevos recursos de lenguaje y códigos bien precisos.

Tanto en las listas de discusión por correo electrónico, en los chat y en la Web en general, pareciera que los usuarios de alguna forma han recuperado aquel territorio «perdido» de la palabra oral. Al usuario miembro de una lista o activo partícipe de un chat, no le interesa tanto lo que define un discurso como verdadero sino aquello que su presencia en palabras escritas provoca. El acto de escribir se convierte en un proceso creativo, intensamente imaginativo y experimental. Aquí es donde se revela la ironía de otro punto: «la Red nos brinda una experiencia de la escritura que actualiza una dinámica de comunicación semejante a las prácticas de la tradición oral» (4).

Otra de las peculiaridades en la comunicación virtual es la ausencia del contexto. No existen referentes externos, no hay nada que oír, nada que ver o tocar, todo lo que hay son palabras que deben servir tanto para definir como para representar. La ausencia de un marco compartido y las características impersonales de la escritura como medio de comunicación hacen de la identidad de sus participantes una incógnita.

La falta de un contacto físico, cara a cara entre sus participantes, planteó la necesidad de crear una simbología universal que expresara los sentimientos y las emociones de los usuarios. Surgen los smileys, gráficos creados a través del teclado que se encargan de reflejar los diferentes estados de ánimo de los usuarios y que contribuyen a definir la relación entre los comunicantes.

\begin{tabular}{|c|l|}
\hline$(-)$ & Alegría \\
\hline$\odot$ & Tristeza \\
\hline$:-D$ & Reír \\
\hline$:^{\prime}($ & Llorar \\
\hline
\end{tabular}


ORIGINALES Y REVISIONES

Como podemos observar se han trastocado las formas tradicionales de relacionarse entre los sujetos, y uno de los elementos más sobresalientes dentro de las posibilidades que brinda Internet son los chat de conversación, a través de los cuales son posibles las relaciones interpersonales. El chat, como cualquier otro espacio de interacción, está sujeto a un sistema de reglas de comunicación: conversacionales, normativas, lingüísticas y rituales.

Las reglas conversacionales se expresan a través de contratos de comunicación donde los participantes «pactan» las reglas y los principios implícitos del intercambio (por ejemplo el no tolerar insultos o agravios, la publicación de datos confidenciales de terceras personas; con formas de exclusión interactiva si surgiera el caso); actúan de reguladores. El único requisito obligatorio es el de la elección de un apodo o nickname para el reconocimiento del usuario.

Las reglas normativas tienen carácter prescriptivo, estando los miembros de una comunidad sujetos a ciertas obligaciones que condicionan las relaciones de sus pares.

Para lograr que la interactividad se convierta en un proceso fluido, informal y divertido surgen nuevas reglas lingüísticas, como el modificar la construcción morfológica de las palabras sin alterar la pronunciación fonética, transcribir diferentes sonidos onomatopéyicos para expresar sensaciones, simular la presencia de objetos en la conversación y recursos gráficos (caras, iconos, ruidos). Las reglas rituales constituyen un sistema convencional propio de cada cultura (la cortesía, el buen trato).

\section{El nacimiento de «una nueva cultura»}

En los últimos cuarenta y cinco años de historia, con la aparición de Internet y su precursor, Arpanet, en 1969 (concebido por investigadores militares estadounidenses ante la amenaza de la guerra fría, como red computacional) hemos asistido a una verdadera «revolución cultural» que se ha ido gestando gracias a la miniaturización y democratización de los ordenadores, a su creciente interconexión (mediante la creación de una auténtica telaraña mundial: La World Wide Web, a su conversión multimedia (la mezcla de iconos escritos, visuales y sonoros en hipertextos en constante transformación) y su impacto cultural marcado por una profunda reestructuración de los estilos de vida y valores; desde una sociedad de economía industrial (que comenzaba a cuestionar los fundamentos ideológicos, religiosos y morales sobre los que se había construido la civilización contemporánea) a otra de economía informacional, de la cultura del ahorro a la de consumo, de la puritana a una hedonista, de la patriarcal a una pluralista y segmentada, de la 
oral y escrita a la audiovisual y multimedia, de una local a culturas globalizadas, de la cultura presencial (cara a cara) a una virtual (interacción electrónica) (5).

En la década de los ochenta el ordenador pasó a ser un instrumento de uso cotidiano (como lo fuera dos décadas antes la televisión); en 1990 se difunde Internet gracias al correo electrónico y tras superar el miedo milenarista del llamado «efecto 2000» (el temor al colapso informático motivado por haber programado el calendario de las computadoras con dos dígitos) se impone como nuevo modelo cultural.

Paralelamente al desarrollo tecnológico y a su expansión hacia los órganos gubernamentales, las universidades y finalmente los hogares, surgen grupos sociales marcados por la nueva infraestructura material emergente. Entre ellos destacan los hackers (1960), apasionados del ordenador, que ponen sus conocimientos informáticos al servicio del desarrollo libre y sin barreras de la «sociedad-Red», prototipos de un nuevo concepto de moralidad con una ética («nética») propia: relación libre con el tiempo, concepción lúdica del trabajo, descentralización, rechazo a jerarquías, a la pasión y a la experiencia (6); los hikikomori (que significa «encerrarse en uno mismo», 1990) en los países altamente desarrollados como Japón (1\% de la población total, 10\% de la población de esas edades en el 2002). Jóvenes de unos veinte años que, al finalizar sus estudios, no quieren enfrentarse a una vida profesional basada en la competencia y optan por no salir de su habitación, conectados a internet de manera indefinida, encontrando en la dialéctica entre el Yo y la Red el refugio necesario para dar sentido a su propia existencia. Con el tiempo se va imponiendo un nuevo concepto de generación moderna: la Generación@ que se sustenta sobre tres pilares fundamentales: El acceso universal a los nuevos modelos de comunicación. La ambigüedad (erosión entre los géneros y los sexos; muchos jóvenes utilizan el símbolo para significar el término neutro). La globalización.

\section{Psicopatología asociada a Internet}

En 1969 Joseph Weizembaum (7) habla de los adictos a la informática como «Bohemios de las computadoras» 0 «Programadores compulsivos» para referirse a los integrantes más jóvenes del laboratorio de inteligencia artificial del Massachussets Institute of Technology.

En los años setenta se desarrollan estudios encaminados a definir el perfil del informático de la época $(8,9,10)$ poniendo de manifiesto peculiaridades tales como la baja empatía o el aislamiento social. La búsqueda de rasgos de personalidad comunes entre los usuarios lleva a los investigadores a estudiar a los jugadores de los videojuegos, aunque con resultados poco relevantes. 
ORIGINALES Y REVISIONES

Existen dos tipos de usuarios de Internet: los regulares (se conectan prácticamente a diario, 4 veces/semana, manteniendo actividades regulares e invirtiendo en torno a 10 horas semanales en esa actividad) y los ocasionales (esporádicamente).

El navegante tipo español sería un varón (77.7\%) observándose una progresiva incorporación de la mujer, con una edad entre los 20-44 años (78.5\%) con ingresos propios $(72.4 \%)$, nivel de formación correspondiente a estudios universitarios $(56.3 \%$ ) o de segundo grado $82 \%$ ) que vive en el medio urbano (según la encuesta AIMC: Asociación para la Investigación de los Medios de Comunicación).

El concepto de adicción a Internet surge a partir de la lista de correo IASG (Internet Adicción Sport Group) moderada por Ivan Goldberg (1995) (11) y finalmente asentado gracias a la dra. Kimberly S. Young (12) con la publicación: The Emergence of a New Clinical Disorder. En el DSM-IV (APA, 1994) viene recogida dentro de los «Trastornos del control de los impulsos sin otra especificación: adicción/compulsión por Internet» (13).

Muchas personas pasan casi todo su tiempo de vigilia frente al ordenador. Sus patrones de uso son repetitivos y constantes, y son incapaces de reprimir las intensas ansias de utilizar el ordenador o de navegar por la Red. Los adictos a Internet pueden sentirse atraídos por ciertos sitios que satisfagan necesidades especificas (compras, sexo, juegos interactivos); la compulsión hacia los videojuegos sería una variante de este patrón de conducta (13).

Davis (14) presenta un modelo cognitivo-conductual que trata de superar el concepto de dependencia de Internet, hablando de «uso patológico» señalando dos formas clínicas de presentación: generalizada y específica. Los primeros serían sujetos con dificultades crónicas en el contexto social, aislados y que invierten su tiempo en la Red en una actividad no orientada a ningún propósito concreto, convirtiéndose en su única conexión con el mundo exterior; con frecuencia con antecedentes psiquiátricos. Los segundos, aquellos en que entidades clínicas previas (juego patológico, uso excesivo de pornografía) se ven exacerbadas, siendo Internet el vehículo de los síntomas.

Los criterios diagnósticos propuestos se basan en la tolerancia (definida por la necesidad de incrementar las cantidades de tiempo conectado para lograr satisfacción y la disminución del efecto con el uso continuado de similares tiempos de conexión), la dependencia y el síndrome de abstinencia; existen propósitos persistentes de suprimir o controlar el acceso a la Red; inversión de tiempo notable en actividades relacionadas; disminución o desaparición de actividades sociales, profesionales o de recreo; permanencia conectado a pesar de saber que ello supone un problema persistente y recurrente de tipo físico, laboral, social, etc. 
Se han propuesto algunos mecanismos psicológicos que favorecerían el hábito: aplicaciones más o menos atractivas para el usuario (fundamentalmente el chat y los juegos MUD: Multi User Dungeon); el apoyo social y la rapidez a la hora de formar grupos en el ciberespacio, existiendo «una pérdida de miedo al rechazo»; la satisfacción sexual con interacciones eróticas reforzadas desde el anonimato y la desinhibición: «sexo libre y seguro»; la creación de personalidades ficticias como «forma de afrontar las propias inseguridades personales»; la expresión de aquellos aspectos reprimidos $\mathrm{u}$ ocultos que definen «personalidades reveladas»; el reconocimiento y el poder.

Desde el punto de vista de la máquina, algunos investigadores barajan la idea de que existen características propias de Internet con efecto sobre la conducta de los usuarios: modelo ACE (Anonimato, Conveniencia y Escape) (15).

La accesibilidad, velocidad e intensidad con la que se nos vuelca la información, favorecida por la creación de una realidad alternativa, formarían parte de esa influencia. Otra vía reside en considerar la existencia de un uso abusivo de la tecnología en general, que podría evolucionar de modo adaptativo (uso intensivo de sus ordenadores, teléfonos móviles) o bien desviarse hacia situaciones desadaptativas de forma generalizada o específica.

Se han descrito factores de riesgo de vulnerabilidad psicológica asociada como son la introversión y la baja autoestima, el alto nivel de búsqueda de sensaciones nuevas, la susceptibilidad, la timidez y la fobia social; en contrapartida, la primera aplicación terapéutica de realidad virtual en España, fue en el tratamiento de trastornos de la conducta alimenticia y fobias en el Centro Médico Delfos-SITEC con gran éxito. Se utiliza la realidad virtual inmersiva e interactiva, es decir, que mediante unos cascos de alta resolución, el paciente se introduce en los escenarios en los que siente pánico y fobia y progresivamente, en las situaciones en las que se pretende implementar cambios en las estrategias de afrontamiento. Se considera que el grado de mejora y de prevención de recaídas con esta metodología puede tener el doble de éxito que las metodologías tradicionales; los pensamientos abstractos, la atención dispersa; las adicciones químicas o psicológicas presentes o pasadas; la reactividad emocional, los comportamientos obsesivo-compulsivos y las alteraciones del estado de ánimo, fundamentalmente, la depresión.

Los efectos negativos de la comunicación establecida en la Red son: el aislamiento social con empobrecimiento de las relaciones interpersonales (con formas de exclusión cibernéticas: para acceder a la Red necesitamos «clave de acceso»); el aislamiento familiar y laboral; la alteración en los ritmos circadianos (sueño, transformación hábitos alimenticios, etc.); síndromes ansiosos; reforzamiento de estados depresivos; irritabilidad y conductas agresivas. 
ORIGINALES Y REVISIONES

Ante una situación de abuso de cualquier recurso de Internet debemos proceder a descartar el hecho de que dicha conducta no sea debida a otra entidad nosológica primaria, cuyo tratamiento sea suficiente para extinguir dicha conducta.

Especial atención se debe prestar a aquellos casos en el que el manejo de los recursos tenga un papel instrumental, apareciendo como elementos sintomáticos de diversos trastornos de la conducta que suelen englobarse en cuadros de tipo caracterial. Debemos destacar también los que aparecen en el contexto de trastornos del contenido del pensamiento de carácter autorreferencial o persecutorio (16).

\section{Conclusión y reflexiones}

La salud mental de una persona, desde el punto de vista de la comunicación interpersonal, se sustenta en cuatro pilares fundamentales: la interacción y adaptación con la familia de origen; con la familia propia; en las relaciones laborales; en la capacidad de pertenecer a una red social estable (apoyo social percibido).

Si las nuevas tecnologías, como cibercultura, ya están formando parte de esa realidad como un factor ambiental más es lógico pensar que, rigiéndose por sus propias reglas, en un futuro no muy lejano, determinen las conductas y las cogniciones de los individuos, creando patrones propios de personalidad, que se considerarán como «normales» o «patológicos» en función de la conciencia global. En la actualidad se hace necesaria la reflexión si «la interacción entre el hombre y la máquina» debe contemplarse como un quinto pilar de salud mental.

En el proceso adaptativo de esta nueva cultura de carácter figurativa, donde los adultos aprenden de los jóvenes, y éstos a su vez asumen una nueva autoridad mediante la captación de un futuro aún desconocido, probablemente esté el origen de la psicopatología asociada al mundo virtual y tal vez sea un factor determinante de lo biológico o genético en las generaciones venideras. No hay que olvidar que la realidad virtual, desde la mirada de un niño en la era digital, acostumbrado a que el proceso de comunicación sea interactivo, probablemente sea muy distinta a la que hemos vivido la «generación de la transición».

La problemática existente entre si hay o no patología asociada a la Red, si son válidos sus conceptos, si la metodología llevada a cabo en los distintos estudios realizados tienen la validez científica suficiente como para poder ser tenidos en cuenta, no son más que parte, como si de una pieza quirúrgica se tratase, de una problemática mucho más profunda, y que concierne directamente a la propia esencia del ser humano en su proceso evolutivo como especie y su adaptación a los cambios. 
En la transformación del lenguaje, hacia formas de comunicación donde lo importante no es lo que se siente y expresamos de forma racionalizada a través de la palabra sino exclusivamente lo que se transcribe, está la cima del iceberg del cambio acelerado social y de la incorporación de las nuevas tecnologías como cultura.

¿Está el clímax tecnológico en el momento histórico en el que la ciencia, a través de la genética, «clone» al nuevo ser humano como finalización del proceso de «culturización-colonización» tecnológica? «La conexión umbilical virtual» estará establecida, relegando a un segundo plano el concepto de individualidad que nos define a cada ser humano y que nos convierte en seres únicos, para pasar a ser productos y subproductos del ya iniciado proceso globalizador.

Se ha planteado de forma terapéutica el uso de Internet en el tratamiento de la fobia social basándose en las características que oferta la Red para la comunicación desde el anonimato y la desinhibición. La comunicación interactiva, desde la proxémica, se alejaría del individuo, planteando una barrera física en el propio acto de comunicar; cuanto más nos separamos de la individualidad del otro, en el «cara a cara», más seguros nos sentimos pero más nos alejamos de nuestra propia «zona íntima» donde la riqueza del lenguaje adquiere su máxima expresión. Resulta ser un problema de elección. Preferimos dar una realidad alternativa a ese tipo de pacientes, una máscara a sus propios miedos e inseguridades o como terapeutas deberíamos ayudarles a encontrar los caminos necesarios para vencer la incertidumbre que supone el enfrentarse a uno mismo y a la particular forma de entender la realidad.

Tenemos la responsabilidad con las generaciones venideras de «educar» desde la conciencia, de forma activa, sobre el uso racional y crítico de lo tecnológico y su representación en un mundo virtual paralelo impuesto por el propio devenir de la conciencia global humana. Lo que está en juego no es la validez de la ciencia y sus principios, ni su expresión en lo tecnológico, sino el poder elegir libremente cómo queremos ser como individuos y como humanidad en el futuro.

\section{BIBLIOGRAFÍA}

(1) Kaplan, H.; Sadock, B., Tratado de Psiquiatría, Buenos Aires, Intermédica, 1997, 6. a ed.

(2) Watzlawick, P.; Helmick, J.; JaCKSON, D., Teoría de la comunicación humana: interacciones, patologías y paradojas, Barcelona, Herder, 1981.

(3) Merino, J., y otros, Curso de relación médico paciente. Universitas Miguel Hernández: Comunicación verbal y no verbal, Alicante, Medina Ferrer, 2005.

(4) Lameiro, M.; Sánchez, R., «Vínculos e Internet», Campo Grupal, n. ${ }^{\circ} 1$, julio-agosto, 1998.

(5) FeiXa PÁmpols, C., «Los nuevos modelos culturales», Historia Universal. Fin de Siglo. Las claves del siglo XXI, Madrid, Salvat, 2004. 
(6) Himanen, P., La ética del hacker, Barcelona, Destino, 2002.

(7) Weizembaum, J., Computer Power and Human Reason: From Judgement to Calculation, San Francisco, W.H. Freeman, 1976.

(8) BARNES, P., «A Study of Personality Characteristics of Selected Computer Programmer and Computer Programmer Trainees», Dissertation Abstracts, 1974, 3(3-A), p. 1440.

(9) Cross, E. M., «The Behaviour Styles, Work Preferences and Values of an Occupational Group: Computer Programmers», Dissertation Abstracts, 1972, 32(7-B), pp. 4273-4274.

(10) Miller, J., «Selecting Computer Programmers: a Multivariate Approach to the Determination of Predictors Using an Improved Criterion for on-The-Job Success of Male and Female Computer Programmers», Dissertation Abstracts, 1970, 31(4b), pp. 2341-2342.

(11) Goldberg, I., Internet Addiction Disorder-Diagnostic Criteria. Internet Addiction Support Grou, 1995.

(12) Young, K. S., «Internet Addiction: the Emergence of a New Clinical Disorder», Comunicación presentada en la 104th Annual Convention of the American Psychological Association, Toronto, 1996.

(13) FIRST, M. B., y otros, DSM-IV-TR. Manual de diagnóstico diferencial, Barcelona, Masson, 2002.

(14) DAVIs, S. F., y otros, «An Examination of Internet Usage in Two College Campuses», College Student Journal, 1999, 33(2), pp. 257-260.

(15) Young, K. S., «Psychology of Computer Use Addictive Use of The Internet: A Case that Breaks the Stereotype», Psychological Reports, 1996, 79, pp. 899-902.

(16) Esallo Martí, J. A., «Usos y abusos de internet», Ponencia presentada en el II Congreso Psicología e Internet, Toledo, 25 de marzo, 2000.

* David García Gutiérrez, M.I.R. de Medicina Familiar y Comunitaria; José Luis Hernández Fleta, psiquiatra; Adriana Salesansky Davidovdsky, psiquiatra; José Manuel Brito Jinorio, psiquiatra; Tomás Sánchez-Araña Moreno, M.I.R. de Psiquiatría. Unidad de Salud Mental de Canalejas. Las Palmas de Gran Canaria.

Correspondencia: Dr. David García. Avenida Escaleritas N. ${ }^{\circ} 54$ Portal B, Escalera 6, 4. ${ }^{\circ} \mathrm{C} .35011$ Las Palmas de Gran Canaria.dgg_1976@wanadoo.es 